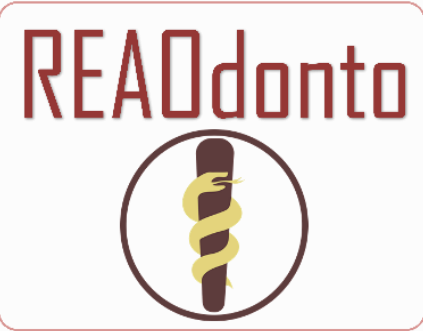

Revista Eletrônica Acervo Odontológico

\section{REVISÃO BIBLIOGRÁFICA}

Recebido em: 9/2020

Aceito em: 10/2020

Publicado em: 12/2020

\title{
Manchas extrínsecas negras em dentes deciduos e permanentes: revisão da literatura
}

\author{
Black extrinsic spots on decided and permanent teeth: literature review
}

Manchas extrínsecas negras en dientes decididos y permanentes: revisión de la literatura

Thaís Amaral Carvalho ${ }^{1 *}$, Géssica Kerolayne da Silva de Oliveira ${ }^{1}$, Kathleen Hayden Oliveira de Medeiros ${ }^{1}$, Pedro Rauel Cândido Domingos ${ }^{1}$.

\begin{abstract}
Resumo: As manchas extrínsecas pigmentadas negras (MEPN) são caracterizadas como pontos pigmentados, de coloração negra, que ocorrem em diferentes localizações da arcada, comprometendo a estética dentária do paciente. Neste artigo foi investigado as causas, o diagnóstico e o tratamento das MEPN, objetivando contribuir com uma maior compreensão sobre o assunto. Atualmente, com a evolução da estética odontológica, aumentou a procura e melhorou o acesso ao cirurgião dentista para tratar situações como as MEPN. A ocorrência das MEPN é relacionada na literatura a presença de alguns microrganismos, como os Actinomyces sp. e a Prevotella Melaninogenicas, na composição do biofilme oral, assim como a dietas ricas em substâncias utilizadas por esses microrganismos para a produção do pigmento, como o Cálcio e Ferro, principalmente. O diagnóstico da MEPN é realizado clinicamente, sendo o diagnostico laboratorial considerado padrão ouro a cultura microbiana, possibilitando a identificação e o teste de sensibilidade. Associada a ocorrência das manchas está um fator protetivo contra cáries promovido por este biofilme específico. Dentre os tratamentos disponíveis, técnicas abrasivas são as mais utilizadas, mas não resolvem os problemas de reincidivas, comuns aos pacientes afetados, sendo o atual desafio a ser superado por novas metodologias que venham a ser desenvolvidas.
\end{abstract}

Palavras-chave: Pigmentação dentária, Bactérias cromogênicas, Manchas extrínsecas.

\begin{abstract}
Extrinsic black pigmented spots (EBPS) are characterized as pigmented spots, black in color, that occur in different locations of the arch, compromising the patient's dental aesthetics. In this article, the causes, diagnosis and treatment of EBPS were investigated, aiming to contribute to a greater understanding of the subject. Currently, with the evolution of dental aesthetics, demand has increased and improved access to the dental surgeon to treat situations such as EBPS. The occurrence of EBPS is related in the literature to the presence of some microorganisms, such as Actinomyces sp. and Prevotella Melaninogenicas, in the composition of oral biofilm, as well as diets rich in substances used by these microorganisms for the production of pigment, such as Calcium and Iron, mainly. The diagnosis of EBPS is performed clinically, with the laboratory diagnosis being considered the gold standard for microbial culture, enabling identification and sensitivity testing. Associated with the occurrence of spots is a protective factor against cavities promoted by this specific biofilm. Among the treatments available, abrasive techniques are the most used, but they do not solve the recurrence problems, common to the affected patients, being the current challenge to be overcome by new methodologies that may be developed.
\end{abstract}

Keywords: Dental pigmentation, Chromogenic bacteria, Extrinsic stains.

\footnotetext{
${ }^{1}$ Centro Universitário do Norte (UNINORTE), Manaus - AM.

*E-mail: thays4929carvalho@gmail.com
} 
Resumen: Manchas pigmentadas negras extrínsecas (MPNE) se caracterizan por ser manchas de color negro, que ocurren en diferentes localizaciones del arco, comprometiendo la estética dental. En este artículo se investigaron las causas, diagnóstico y tratamiento de MPNE, con objetivo de contribuir a una mayor comprensión del tema. Actualmente se ha incrementado la demanda y se ha mejorado el acceso al dentista para tratar situaciones como la MPNE. La ocurrencia de MPNE está relacionada con la presencia de algunos microorganismos, como Actinomyces sp. y Prevotella Melaninogenicas, en la composición de biofilm oral, así como dietas ricas en sustancias utilizadas por estos microorganismos para la producción de pigmentos, como Calcio y Hierro, principalmente. El diagnóstico de MPNE se realiza clínicamente, y el diagnóstico de laboratorio se considera el estándar de oro para el cultivo microbiano, lo que permite la identificación y las pruebas de sensibilidad. La aparición de manchas es un factor protector frente a las caries, favorecido por este biofilm específico. Entre los tratamientos, las técnicas abrasivas son las más utilizadas, pero no resuelven los problemas de recurrencia, comunes a los pacientes afectados, siendo el desafío actual a ser superado por nuevas metodologías que se puedan desarrollar.

Palabras clave: Pigmentación dental, Bacterias cromogénicas, Manchas extrínsecas.

\section{INTRODUÇÃO}

Manchas extrínsecas pigmentadas negras (MEPN) geralmente são localizadas e, rigidamente aderidas, as superfícies do esmalte dentário, podendo estar presente nos dentes decíduos e permanentes, mais frequentemente nas dentições decíduas (COSTA LMSF, 2019). Os agentes etiológicos mais comuns associados a essas alterações de cor dentária são bactérias cromogênicas (BC) como as Actinomyces sp. e a Prevotella melaninogenica, as quais realizam deposição de sais ferrosos, procedentes da dieta do paciente, após metabolização por essas bactérias, compondo a pigmentação das manchas na superfície dos dentes, dando início a problemas estéticos (MORIMOTO S, et al., 2018).

Caracterizadas como pontos pigmentados de coloração negra, localizadas nas regiões cervicais de vestibulares, palatinas ou linguais dos dentes, podendo chegar até sua oclusal, e frequentemente encontrada nos dentes posteriores, podendo evoluir para os dentes anteriores, o que consequentemente compromete a estética dentária do paciente. Vários estudos mostram que os índices de cárie diminuem com a presença das $\mathrm{BC}$, uma vez que o aumento da presença de bactérias formadoras dos pigmentos está associado a diminuição de bactérias causadoras da cárie, o que pode explicar essa ausência da doença cárie naqueles afetados com as MEPN (MORIMOTO S, et al., 2018). Segundo Costa LMSF (2019), pigmentações dentárias variam em diversos parâmetros, tais como sua etiologia, localização, composição, intensidade e grau de adesão, e que estas informações auxiliam no seu diagnóstico. Outras informações importantes ao diagnóstico estão relacionadas as características clínicas visuais, podendo-se realizar exames de culturas bacterianas, muito usada na odontologia, para identificar a presença de BC.

Não há consenso na literatura sobre sua etiologia e epidemiologia, visto a diversidade de fatores envolvidos, no entanto existem relatos que comprovam o envolvimento de $\mathrm{BC}$ na composição de biofilmes relacionados as manchas, sendo a principal causa relacionada (OLIVEIRA LR, 2001). Além disso, entendemos que a microbiota oral é notavelmente diversa e complexa, sendo estimado mais de 700 espécies de microrganismos que podem ser encontrados na cavidade oral, uma parte pertencente ao periodonto, enquanto os demais habitariam outros microambientes, como a língua. $O$ biofilme de pacientes com MEPN possui elevados níveis de substâncias oriundas da alimentação, além de outros fatores que os diferenciam de biofilmes considerados normais, sendo assim classificado como biofilmes especiais (BEDRAN LBT, et al., 2010).

O presente trabalho teve por objetivo relatar, através de levantamento bibliográfico a partir de artigos científicos, as etiologias possíveis para as manchas extrínsecas dentárias, destacando os microrganismos e os tipos de tratamentos ofertados ao longo dos anos.

\section{MÉTODOS}

Foi realizada pesquisa exploratória, de cunho científico, em revisões bibliográficas e casos clínicos referentes ao tema proposto, utilizando os portais Google Acadêmico, Scientific Electronic Library Online 
(SCIELO) e Literatura Latino-Americana e do Caribe em Ciências da Saúde (LILACS). O estudo teve início em abril de 2020 e foi finalizado em outubro do mesmo ano, onde foi utilizado os seguintes descritores: bactérias, cromogênicas, orais, dentais, manchas e biofilme. As buscas foram realizadas utilizando diferentes associações dos descritores, como "bactéria cromogênica", "manchas dentais extrínsecas", "manchas dentais negras", "biofilme oral manchas", "chromogenic bacterium", "black dental stains", "oral biofilm stains" e "extrinsic dental stains". A busca incluiu obras em língua portuguesa e inglesa referentes ao tema a fim de ampliar o conteúdo para desenvolvimento da revisão. Foi realizado uma triagem inicial, sendo selecionados aqueles que atendiam aos critérios de inclusão, sendo excluídos dessa seleção aqueles que se enquadravam nos critérios de exclusão (Quadro 1).

Quadro 1 - Critérios de inclusão e exclusão utilizados na seleção de artigos e organização dos tópicos da revisão.

\begin{tabular}{|l|l|}
\hline \multicolumn{1}{|c|}{ Inclusão } & \multicolumn{1}{c|}{ Exclusão } \\
\hline - Pesquisas realizadas em humanos. & - Pesquisas feitos em animais. \\
- Artigos nacionais e Internacionais. & - Artigos com pouco conteúdo explicativo. \\
- Artigos publicados de 2010 a 2020. & - Artigos de revisão com conteúdo repetido. \\
- Novas técnicas de tratamentos. & - Textos não disponíveis. \\
\hline
\end{tabular}

Fonte: CARVALHO TA, et al., 2020.

A associação de descritores que obteve melhores resultados foi "bactérias cromogênicas" e "manchas extrínsecas", sendo utilizada como abordagem principal na seleção e organização do assunto. Um total de 917 publicações foram submetidas a seleção que considerou a importância dos resultados, o ineditismo da informação, a relação com o tema proposto, além da exclusão de publicações com redundância nos resultados, sendo utilizados 22 publicações na presente revisão da literatura (Figura 1).

Figura 1 - Fluxograma das etapas de busca e organização de resultados da pesquisa realizada nas bases de dados propostas.

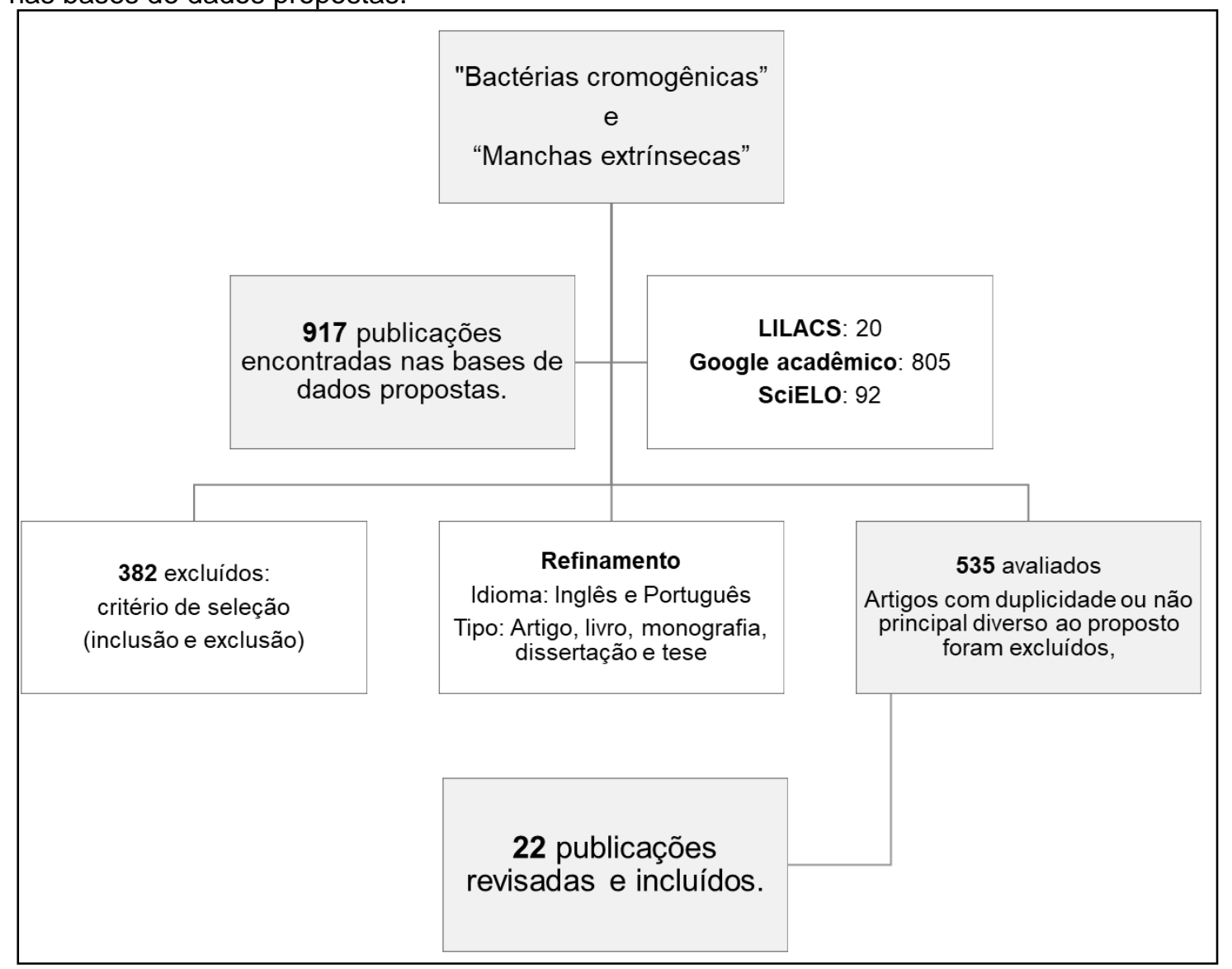

Fonte: CARVALHO TA, et al., 2020. 


\section{RESULTADOS E DISCUSSÃO}

As manchas pigmentadas negras em dentes de pacientes apresentam-se, geralmente, como linhas ou faixas enegrecidas na face lingual, próximo a margem gengival, podendo apresentar-se de maneira contínua, localizada ou, ainda, em forma de linhas pontilhadas. Sua remoção é complexa e envolve procedimentos que não são utilizados, geralmente, na profilaxia diária (HATTAB FN, et al., 1999; HEINRICH-WELTZIEN R e BARTSCH SEB, 2014).

As manchas extrínsecas podem aparecer em qualquer momento da vida, tanto na dentição decidual mista ou até na permanente, independente do sexo (SHOURIE KL, 1947). As áreas atingidas são, na maioria das vezes, de difícil acesso, como em sulcos, fóssulas e fissuras dentárias, sendo necessária a intervenção profissional para tratá-las (CALDAS CT, et al., 2008). Os pigmentos dentais enegrecidos, nada mais são que o resultado de reações que ocorrem entre bactérias específicas presentes no biofilme oral e substratos vindos do meio externo, como da alimentação (HASSAN A, et al., 2011).

A ocorrência desses pigmentos é associada a microrganismos específicos denominados de cromogênicos, dos quais bactérias do gênero Actinomyces e da espécie Prevotella Melaninogenicas se destacam quanto a sua prevalência nesses casos. Além da microbiota específica, que irá compor um biofilme especial relacionado a ocorrência dessas manchas, na saliva dos indivíduos afetados são encontradas elevadas concentrações de ferro, o que traria com consequência o substrato necessário ao biofilme para promoção das manchas (COURY E e BANDEIRA SMM, 1998).

\section{Etiologia das manchas extrínsecas}

As manchas extrínsecas negras tem sua etiologia relacionada a presença de microrganismos específicos e a liberação natural de metabólitos desses microrganismos na saliva, os quais favoreceriam as alterações na coloração externa dos dentes, havendo ainda a falta de informações na literatura sobre todos os fatores que levariam ao surgimento dessas manchas (ANRAKU RY e GUEDES CC, 2013).

A partir da análise do fluido salivar pode-se identificar a composição da microbiota oral, a qual é composta majoritariamente, cerca de $90 \%$, por Gram positivos, dos quais $85 \%$ são cocos Gram positivos e $5 \%$ de Streptococcus. Entre os Gram negativos, minoria na composição dessa microbiota, cerca de $4 \%$ seriam de cocos (como as Neisserias) e 1\% de bastonetes Gram negativos, como Bacteroides melaninogenicus. Nos biofilmes relacionados a pigmentação extrínseca também é verificado essa presença maior das bactérias Gram positivas em relação as negativas, com destaque para a presença de bactérias cromogênicas com as Actinomyces, as quais apresentam maior prevalência em isolados de biofilmes relacionados a manchas dentárias negras (ARRUDA GS, et al., 2003).

\section{Identificação de bactérias do biofilme oral}

Os microrganismos precisam estar vivos para serem analisados e identificados, tornando a cultura bacteriana uma ferramenta muito importante no processo de identificação dos patógenos. Cada tipo de microrganismo submetido a cultura possui necessidades nutricionais diferentes, por isso é importante um conhecimento básico a respeito dos possíveis microrganismos a serem identificados na amostra estudada, visto que a coleta, o meio de transporte e de isolamento, assim como os de identificação, irão definir o sucesso na identificação do microrganismo. Para lograr êxito nesse contexto, é realizado um levantamento de informações a respeito dos possíveis patógenos nas amostras e para a definição dos meios de cultura a serem escolhidos, de acordo com cada grupo de microrganismos. A sobrevivência e crescimento deles no meio artificial, observado a partir da formação de colônias em placas ou turvação em caldos, será fundamental para a identificação deles após diversos testes bioquímicos, os quais envolvem outros cultivos em meios sólidos e/ou líquidos (SEHNEM NT, 2015).

Amostras coletadas da cavidade oral no consultório odontológico, onde são realizadas as coletas, são direcionadas a laboratórios de diagnóstico microbiológico em meios de transporte nutritivos, os quais garantem a viabilidade dos microrganismos contidos na amostra e evitam possíveis desidratações ou oxidações da amostra em trânsito. 
O tempo e o acondicionamento das amostras também são muito importantes para o sucesso dos processos de isolamento e identificação dos microrganismos, visto que os microrganismos perdem a vitalidade e capacidade reprodutiva após serem retirados do ambiente de origem, fato contornado, até certo ponto, quando utilizado o meio microbiológico de transporte adequado (JARDIM JUNIOR EG, et al, 2011). Dentre os meios de transporte disponíveis para material biológico para cultura, o VMGA III (Viabilit Medium Goteborg Anaerobically) é sugerido para esse tipo de amostra por ser um meio que permite maior tempo de manutenção dos microrganismos entre a coleta e o semeio, garantindo a viabilidade inclusive de bactérias anaeróbias (SOUSA RBRA, 2014).

A identificação dos microrganismos presentes no biofilme oral é feita a partir do cultivo dos microrganismos, sendo a cultura bacteriana considerada padrão ouro entre as metodologias de identificação bacteriana na odontologia, possibilitando a quantificação bacteriana, a realização de testes de susceptibilidade à antibióticos, além de ser capaz de isolar e detectar novas espécies de microrganismos relacionadas ao problemas em estudo.

Entretanto, existem algumas limitações e desvantagens desse método de diagnóstico, como a necessidade de preservar a vitalidade do microrganismo até a seu semeio, o que deve ser considerado quando o local de coleta e da análise são muito distantes, e a dificuldade de recuperar algumas espécies cultiváveis quando estão em pequena quantidade na amostra coletada, o que ocasiona um pequeno número dessas bactérias na cultura em relação as outras bactérias presentes nesse tipo de amostra, impossibilitando a identificação algumas vezes (BEDRAN LBT, et al., 2010). Outras limitações a essa metodologia estão relacionadas a necessidade de pessoal capacitado para realização das culturas, o longo tempo necessário para o cultivo e identificação e os custos relativamente altos, o que somados as condições rigorosas de transporte e a necessidades de utilizar meios específicos para cada espécie suspeita podem limitar o acesso a essa metodologia (BEDRAN LBT, et al., 2010).

Outras metodologias, além da cultura microbiana, podem ser aplicadas no diagnóstico microbiológico, os quais variam em disponibilidade, custos, em sensibilidade e especificidade. Testes utilizando amostras orais podem possibilitar a deteç̧ão e quantificação de ácidos nucleicos, como em técnicas de Reação em cadeia da Polimerase (PCR), podem identificar as bactérias a partir de padrões conhecidos por meio de Citometria de fluxo ou utilizar algum marcador com Imunofluorescência para evidenciar a presença dessas bactérias nas amostras. Mas é importante destacar que, apesar de muitos desses testes serem mais rápidos e, às vezes, mais sensíveis e específicos do que a cultura, os custos com insumos e pessoal qualificado tendem a ser maiores (CORTELLI SC, et al., 2000).

\section{Diagnóstico da Mancha Extrínseca Negra}

Os pigmentos ocorrem com maior frequência em elementos inferiores nas faces linguais, por existir um contato direto do fluxo salivar, vindo das glândulas salivares submandibulares, e o órgão dentário desta arcada, o que facilita o acúmulo dos substratos vindos da alimentação, assim como dos microrganismos. Esta região de maior acúmulo confere um ambiente mais favorável a formação do biofilme, o qual pode se estender até regiões vestibulares dos elementos dentários, comprometendo sua estética, um dos principais motivos da procura pelo cirurgião dentista (BRANCO CMCC, et al., 2016).

A coloração escurecida das manchas extrínsecas se dá por uma reação causada pelo sulfato de ferro presente na saliva e o sulfeto de hidrogênio produzido pelas bactérias cromogênicas, formando então o sulfato férrico, composto que se adere a superfície do esmalte dentário, formando os vários pontos pretos enfileirados que se localizam principalmente nas porções cervicais do órgão dentário, onde há maior acúmulo de biofilme contribuindo para essa alteração (QUEIROZ GL, et al., 2016).

Alguns fatores como defeitos de esmalte dentário, também podem contribuir fortemente com o acúmulo de placa envolvendo os pigmentos, o que acaba dificultando sua remoção caseira com auxílio de escova dental e creme dental (CABRITA GM, 2012).

Em estudo onde foram examinadas 1.097 crianças, com idade entre 13 e 15 anos, foi verificado pigmentação negra em 156 delas, e classificou a presença das manchas, ou a falta delas, seguindo o

REAOdonto | Vol. 2 | e5915 | DOI: https://doi.org/10.25248/REAOdonto.e5915.2020 Página 5 de 7 
seguinte parâmetro: 1 - sem linhas; 2 - incompleta coalescência das manchas pigmentadas; 3 - linhas contínuas de placas pigmentadas, padronizando e facilitando a sua identificação e localização (OLIVEIRA LR, 2001). Koch MJ, et al. (2001) desenvolveram um método para classificar as manchas extrínsecas em Odontopediatria de acordo com o seu diâmetro: pontos escuros com diâmetro menor que $0,5 \mathrm{~mm}$ formando uma pigmentação contínua, próxima a margem gengival, em superfícies lisas e em pelo menos dois dentes distintos sem apresentar cavitação de esmalte.

\section{Relação da pigmentação dentária e a baixa prevalência a cárie}

Um estudo foi conduzido em crianças (6 a 12 anos), as quais foram divididas em dois grupos, um formado por crianças com pigmentação extrínseca dentária e outro com crianças sem essa pigmentação, foi analisado a relação entre a ocorrência de cáries e das manchas, a fim de se estabelecer alguma relação entre os dois achados. No grupo que apresentava pigmentação extrínseca foi observado menor prevalência de cáries, havendo inclusive indivíduos com ausência dessa patologia, em comparação ao grupo formado pelas crianças sem pigmentação, o qual apresentava prevalência normal dessa doença (CALDAS CT, et al. 2008).

A relação entre a produção de biofilme e a ocorrência de pigmentos nos dentes já foi destacada, assim como as elevadas concentrações de sais de Ferro e de Cálcio, além de fosfatos. Essas substâncias, relacionadas à presença do biofilme, também são associadas a proteção contra microrganismos causadores da cárie (MORIMOTO S, et al., 2018). Com o aumento dos níveis de cálcio e fosfatos nos biofilmes relacionados às manchas negras, notou-se uma diminuição na presença de cáries nestes indivíduos, isso se dá pela diminuição na desmineralização que ocorre durante o processo da cárie dentária, aumentando, consideravelmente, sua capacidade tampão e se tornando uma proteção ao elemento dentário (BROCCA VAO, 2018).

\section{Tratamento para manchas extrínsecas negras}

As manchas extrínsecas precisam ser removidas, visto que elas se tornam um depósito de pigmento irritante para a gengiva marginal, além do comprometimento estético, uma vez que manchas escuras acabam se destacando com facilidade na arcada, sendo necessário o implemento de técnicas que envolvem a raspagem com profilaxia utilizando pastas abrasivas (COSTA SC, et al., 1997).

Defeitos de esmalte podem contribuir no acúmulo dos pigmentos negros e dificultar sua remoção, principalmente se essas lesões se mostrarem com certa profundidade. Diante disso, a simples higiene oral caseira não é suficientemente eficaz na remoção das manchas. Para esses casos, uma técnica bastante eficaz no tratamento das manchas pigmentadas é a Microabrasão, a qual é usada em situações de difícil remoção, que consiste na aplicação de uma pasta composta de ácido hidroclorídrico (6\%), pedra-pomes e taças de borracha para serem usadas junto caneta de baixa rotação, a fim de causar uma friç̧ão sobre a mancha, promovendo a sua remoção (CABRITA GM, 2012),

Arruda GS, et al. (2003), em revisão da literatura, apontou que o tratamento mais indicado para manchas extrínsecas negras é a utilização de técnicas abrasivas, a fim de remover as manchas negras aderidas à superfície do esmalte manualmente. $\mathrm{O}$ uso de jatos de bicarbonato de sódio tem se mostrado um método bastante eficaz e menos agressivo sobre a estrutura do esmalte.

Um método que também pode ser usado, segundo Morimoto S, et al. (2018), é iniciar o tratamento com uso de ultrassons e jatos de bicarbonato, seguido de clareamento dentário caseiro com Peróxido de Carbamida (10\%). O clareamento caseiro deve seguir com uma adequação ao protocolo normal, consistindo na inserção do gel clareador tanto nas faces vestibulares dos elementos quanto nas faces linguais, para que toda a superfície do dente seja envolvida pelo gel, incluindo dentes com prótese e com restaurações. O uso do gel clareador no tratamento das manchas extrínsecas negras derivadas de microrganismos objetiva não apenas clarear os dentes, segundo o autor, mas também por se tratar de um material com ação antimicrobiana, levaria a diminuição no crescimento e no metabolismo de algumas bactérias, como as anaeróbias muitas vezes associadas a esse quadro sendo verificado uma diminuição nas recidivas das pigmentações. 


\section{CONSIDERAÇÕES FINAIS}

As manchas extrínsecas pigmentadas negras têm ocorrência associada a presença de microrganismos específicos, encontrados no biofilme oral e que são produtores de pigmentos, sendo favorecida por dietas ricas, principalmente, em Cálcio e Ferro. Não foi encontrado relatos de maior prevalência deste biofilme associados as manchas e algum sexo, mas a relação entre a presença do biofilme e um efeito protetivo contra cáries dentárias foi observado em diversos estudos, que evidenciaram prevalências menores de cáries naqueles que apresentavam esse tipo de manchas. O desenvolvimento de novos tratamentos para manchas extrínsecas deve objetivar os principais problemas associados a terapêutica atual, que envolve os altos custos e as recidivas frequentes aos quais estes pacientes estão sujeitos. Na atualidade a estética dentária está em alta, com uma maior possibilidade de procedimentos e um maior interesse dos pacientes, o que destaca a revisão proposta nesse estudo a fim de trazer um compilado de informações relevantes a prática profissional nesse ramo da odontologia. A busca contínua por inovação e maior conhecimento das relações microbiológicas nos procedimentos odontológicos, estéticos ou não, são fundamentais para a atualização de profissionais que objetivem o melhor atendimento ao usuário.

\section{REFERÊNCIAS}

1. ANRAKU RY, GUEDES CC. Bactérias Cromogênicas - Revisão de Literatura. Revista de Odontologia da UBC, 2013; 3(1): 5-12.

2. ARRUDA GS, et al. Manchas Extrínsecas Negras do Esmalte. Rev Ciênc Med Capinas, 2003; 12(4): 375-380.

3. BEDRAN LBT, et al. Patógenos Periodontais: Comparação entre Cultura Bacteriana e PCR em Tempo Real para Teste Diagnóstico. Rev Odontol Bras Central, 2010; 19(50): 187-191.

4. BRANCO CMCC, et al. Pigmentações extrínsecas negras do esmalte em Odontopediatria. Rev cuba estomatol, 2016; 53(3): 153-161.

5. BROCCA VAO. Frecuencia de pigmentaciones negras extrínsecas y caries dental en niños de una institución educativa del distrito de barranca-lima, 2018. Tese (Graduação em Cirurgião Dentista) - Facultad de Medicina Humana, Universidad Privada Antenor Orrego, Trujillo, 2018; 45 p.

6. CABRITA GM. Abordagem terapêutica de dentes permanentes com manchas e pigmentações em odontopediatria. Dissertação (Mestrado Integrado em Medicina Dentária) - Faculdade de Medicina Dentária (FMD), Universidade de Lisboa, Lisboa, 2012; 47 p.

7. CALDAS CT, et al. Prevalência de manchas dentais extrínsecas negras e sua relação com a cárie dentária em crianças do município de Santa Terezinha de Itaipu - PR. RFO, 2008; 13(2): 22-26.

8. CORTELLI SC, et al. Métodos para detecção de patógenos periodontais. Pós-Grad Ver Fac Odontol São José dos Campos, 2000; 3(1): 97- 104.

9. COSTA LMSF. Pigmentação Dentária Extrínseca Negra. Relato de Caso Clínico (Mestrado Integrado em Medicina Dentária) - Instituto Universitário Ciências da Saúde, Cooperativa de Ensino Superior Politécnico e Universitário (CESPU), Gandra, 2019; 29 p.

10. COSTA SC, et al. Estudo da ocorrência de manchas extrínsecas negras em crianças e sua relaçäo ao baixo índice de cárie dental. Rev odontol Univ St Amaro, 1997; 2(4): 36-38.

11. COURY E, BANDEIRA SMM. Manchas dentárias extrínsecas pretas - Revisão de literatura. Robrac, 1998; 7(24): 26-7.

12. HASSAN A, et al. Evaluation of different detection methods of biofilm formation in the clinical isolates. Braz $\mathrm{J}$ Infect Dis, 2011; 15(4): 305-311.

13. HATTAB FN, et al. Dental discoloration: an overview. J Esthet Dent, 1999; 11(6): 291-310.

14. HEINRICH-WELTZIEN R, BARTSCH SEB. Dental caries and microbiota in children with black stain and non-discoloured dental plaque. Caries Res, 2014; 48(2): 118-125.

15. JARDIM JUNIOR EG, et al. Detecção de microrganismos de infecções bucais: perspectivas e cuidados a serem seguidos. Revista FUNEC Científica - Multidisciplinar, 2011; 1(1): 1-8.

16. KOCH MJ, et al. Black stain and dental caries in schoolchildren in Potenza, Italy. J Dent Child, 2001; 68(5-6): 353-355.

17. MORIMOTO $\mathrm{S}$, et al. Efeito de agentes clareadores na pigmentação extrínseca causadas por bactérias cromogênicas: 10 anos de acompanhamento de caso. RGO - Rev Gaúch de Odontol, 2018; 66(2): 187-193.

18. OLIVEIRA LR. A presença de mancha negra e sua relação com a baixa prevalência de cárie em crianças. Monografia (Especialização em Odontopediatria) - Centro de Ciências da Saúde, Universidade Federal de Santa Catarina, Florianópolis, 2001; 24 p.

19. QUEIROZ GL, et al. Mancha Dental Extrínseca: Revisão de Literatura. Jornada Odontológica dos Acadêmicos da Católica - JOAC, 2016; 2(2).

20. SEHNEM NT. Microbiologia e Imunologia. 1르 ed. São Paulo: Pearson Education do Brasil, 2015; 71 p.

21. SHOURIE KL. Mesenteric line or pigmented plaque; a sign of comparative freedom from caries. J Am Dent Assoc, 1947; 35(11): 805-807.

22. SOUSA RBRA. Avaliação da microbiota de dentes decíduos necrosados utilizando a reação da polimerase em cadeia. Tese (Doutorado em Odontologia) - Faculdade de Farmácia, Odontologia e Enfermagem, Universidade Federal Do Ceará, Fortaleza, 2014; 71 p. 